AULADUNA: Jurnal Pendidikan Dasar Islam

Vol. 8 No. 1, Juni 2021, pp. 66-76

p-ISSN: 2407-2451, e-ISSN: 2621-0282

DOI: https://doi.org/10.24252/auladuna.v8i1a6.2021

\title{
PENANAMAN KARAKTER GEMAR MEMBACA MELALUI ONE DAY ONE DONGENG PADA MASA PANDEMI COVID-19
}

\section{INSTILLING READING INTEREST CHARACTER THROUGH ONE DAY ONE FAIRY TALE DURING THE COVID-19 PANDEMIC}

\author{
Zakaria $^{1}$, Utami Maulida ${ }^{2}$ \\ ${ }^{1,2}$ Program Studi Pendidikan Guru Madrasah Ibtidaiyah, STAI Binamadani Tangerang \\ ${ }^{1,2} \mathrm{JL}$. KH. Hasyim Ashari Gg. Ambon Kavling DPR, No. 236, Tangerang-Banten \\ Email: zakaria@ stai-binamadani.ac.id ${ }^{1}$, utamimaulida@stai-binamadani.ac.id ${ }^{2}$
}

Submitted: 13-03-2021, Revised: 01-06-2021, Accepted: 08-06-2021

\begin{abstract}
Abstrak
Minat membaca harus ditanamkan pada siswa melalui kegiatan yang menyenangkan sesuai dengan karakter dan perkembangan peserta didik. Penelitian ini bertujuan untuk mendeskripsikan secara komprehensif mengenai penanaman karakter gemar membaca melalui one day one dongeng bagi peserta didik sekolah dasar. Penelitian ini merupakan penelitian deskriptif kualitatif dengan menggunakan metode analisis isi/content analysis, yaitu menganalisis bagaimana strategi one day one dongeng dalam menanamkan karakter gemar membaca selama masa pandemi Covid-19. Hasil penelitian menunjukkan metode one day one dongeng merupakan salah satu metode yang dapat diterapkan semua pendongeng baik orang tua atau guru kepada anak-anak untuk menumbuhkan karakter gemar membaca. Dua dari empat jenis dongeng yang familiar digunakan pada anak adalah dongeng binatang (animals tales) dan dongeng biasa (ordinary folktales).Teknik menyimak dalam mengembangkan strategi one day one dongeng yang tepat digunakan adalah menyimak estetik dan menyimak kreatif, sementara membaca adalah membaca gambar, story telling, dan membaca nyaring. Adapun nilai guna dalam penelitian ini sebagai gambaran tentang penanaman karakter gemar membaca dalam kegiatan one day one dongeng dan dapat dijadikan sebagai konsep pembelajaran literasi bagi peserta didik sekolah dasar.
\end{abstract}

Kata Kunci: One Day One Dongeng, Penanaman Karakter Gemar Membaca

\begin{abstract}
Reading interest must be instilled in students through fun activities following their character and development. This study aims to comprehensively explain instilling reading interest by one day one fairy tale for elementary school students. This research was a qualitative descriptive study using content analysis by analyzing how one day one fairy tale strategy instils reading interest during the Covid-19 pandemic. The results indicated that the one day one fairy tale was a strategy that could be applied by all storytellers, both parents and teachers, to instil the reading interest character of students. Two of four types of fairy tales were familiar to students, namely animal tales and ordinary folktales. The listening techniques appropriate in developing one day one fairy tale strategy were aesthetic and creative listening, while reading techniques were reading pictures, telling stories, and reading aloud. The implication of this study is to illustrate the instilling of reading interest character through one day one fairy tale strategy that can be used as a literacy learning concept for elementary school students.
\end{abstract}

Keywords: One Day One Fairy Tale, Instilling Reading Interest Character

How to Cite: Zakaria, \& Maulida, U. (2021). Penanaman Karakter Gemar Membaca melalui One Day One Dongeng pada Masa Pandemi Covid-19. AULADUNA: Jurnal Pendidikan Dasar Islam, 8(1), 66-76. 


\section{Pendahuluan}

Coronavirus Disease (Covid-19) yang melanda di berbagai penjuru wilayah negara membawa dampak yang signifikan, termasuk di Indonesia. Perubahan besar yang terjadi akibat pandemi virus corona juga dirasakan bagi dunia pendidikan. Sistem pembelajaran di Indonesia secara cepat berubah, mulai dari pendidikan dasar sampai pendidikan tinggi menyelenggarakan pembelajaran jarak jauh atau pembelajaran dari rumah (learning from home) (Marwa, Munirah, Angriani, Suharti, Sriyanti, \& Rosdiana, 2020: 217; Nadeak, Naibaho, Sunarto, Tyas, \& Sormin, 2021: 1131; Rahman, Tristiantari, Zakaria, \& Yugafiati, 2020: 605). Belajar dari rumah atau learning from home merupakan kebijakan pemerintah dalam dunia pendidikan guna mengurangi kerumunan orang dan agar peserta didik tetap melaksanakan kegiatan belajar di masa pandemi. Pembelajaran jarak jauh adalah kegiatan belajar mengajar yang dilaksanakan dengan jarak jauh menggunakan teknologi informasi dan komunikasi yang berimplikasi terhadap proses pelaksanaanya (Lutfi, Sumardi, Farihen, \& Ilmia, 2020: 1). Pembelajaran ini sangat membutuhkan perhatian dan bimbingan orang tua, khususnya bagi peserta didik sekolah dasar. Diperlukan waktu yang cukup, motivasi, dan perhatian khusus kepada mereka, sehingga pembelajaran dapat berjalan dengan baik. Bagi banyak orang tua dan guru kegiatan belajar di rumah merupakan pengalaman baru yang memungkinkan terjadinya kendala dalam pelaksanaannya. Salah satunya pemanfaatan teknologi dalam proses belajar mengajar.

Pandemi yang terjadi secara tiba-tiba menjadi masalah tersendiri bagi lembaga pendidikan, seperti ketersediaan perangkat teknologi yang dimiliki oleh lembaga pendidikan, kemampuan pendidik dan peserta didik menggunakan media pembelajaran berbasis teknologi, serta keterbatasan akses internet dalam menunjang proses pembelajaran (Damayanthi, 2020: 190). Dunia pendidikan harus berubah ketika adanya wabah dan zaman yang menuntut manusia untuk mampu memanfaatkan perkembangan teknologi informasi dan komunikasi. Keduanya menjadi satu paket yang bukan lagi pilihan, tetapi wajib dilakukan agar tetap mampu menjalankan tugas untuk mengembangkan pendidikan (Ansori \& Sari, 2020: 12). Pemanfaatan media pembelajaran daring yang diterapkan oleh pendidik selama pandemi Covid-19 pun beragam jenisnya di antaranya menggunakan whatsapp group, zoom, google classroom, google meet, dan lain sebagainya. Namun, ditemukan berbagai kendala seperti kemampuan pendidik dalam penerapan media pembelajaran jarak jauh tersebut, hal ini mengindikasikan bahwa penerapan pembelajaran secara virtual membutuhkan cukup banyak waktu bagi semua pihak untuk memahami dan mengaplikasikan metode pembelajaran yang efektif dan menyenangkan.

Salah satu tantangan bagi pendidik dan orang tua di masa pandemi yaitu menumbuhkan minat membaca peserta didik. Meskipun belajar mengajar jarak jauh, aktivitas rutin membaca bagi peserta didik harus tetap dilaksanakan. Karakter gemar membaca sudah lama diimplementasikan di sekolah melalui Gerakan Literasi Sekolah (GLS). Program membaca selama 15 menit sebelum kegiatan belajar telah dicanangkan oleh Kementerian Pendidikan dan Kebudayan sejak tahun 2016 sebagai bagian dari implementasi dari peraturan Menteri Pendidikan dan Kebudayaan nomor 23 tahun 2015 tentang penumbuhan budi pekerti. Program yang dikenal dengan Gerakan Literasi Nasional (GLN) ini sebagai upaya pemerintah Indonesia dalam meningkatkan kemampuan literasi peserta didik, salah satunya kemampuan literasi membaca.

Membaca merupakan salah satu kemampuan literasi dasar yang harus terus ditumbuhkan selain 5 (lima) literasi lainnya, yaitu literasi numerasi, literasi sains, 
literasi digital, literasi finansial, dan literasi budaya. Literasi merupakan elemen penting dalam menghadapi industri revolusi 4.0. Kemajuan teknologi yang pesat seharusnya dihadapkan pada keterampilan literasi tingkat tinggi (Rahman, Sakti, Widya, \& Yugafiati, 2019: 190). Merujuk pada beberapa studi tentang kemampuan membaca peserta didik Indonesia, salah satunya dipublikasi oleh Progress in International Reading Literacy Study (PIRLS) dan Early Grade Reading Assessment (EGRA) dalam Tahmidaten \& Krismanto (2020: 22) yang menempatkan posisi Indonesia masih berada di bawah negara-negara yang mengikuti penilaian. Data lain yang menjadi perbincangan khalayak tentang posisi Indonesia menempati urutan ke-60 dari 61 negara partisipan survei dalam hal kemampuan literasi yang dirilis oleh World's Most Literate Nations yang dilakukan oleh Central Connecticut State University (2017). Berkenaan dengan hasil studi tersebut, hal ini menunjukkan bahwa karakter gemar membaca peserta didik harus terus ditumbuhkan pada proses belajar mengajar, terutama pada kondisi pandemi saat ini.

Mengembangkan karakter gemar membaca peserta didik harus didukung oleh semua stakeholder yaitu sekolah, orang tua, dan pemerintah (Novari, Ardini, Rostiana, Meliyawati, Widiatmoko, Rohimajaya, Gumelar, \& Sauri, 2020: 647). Kegiatan membaca harus dirancang dengan baik di masa pandemi ini agar karakter gemar membaca peserta didik dapat tumbuh. Penanaman karakter gemar membaca harus dikenalkan pada peserta didik melalui kegiatan yang menyenangkan dan sesuai dengan karakter ataupun perkembangan peserta didik. Kegiatan yang dapat dilakukan untuk menanamkan karakter gemar membaca sebaiknya kegiatan yang bersifat santai, ringan, menarik, bahkan lucu. Salah satu cara yang dapat diterapkan yaitu one day one dongeng. Memilih dongeng sebagai cara untuk menanamkan karakter gemar membaca sebab di dalam dongeng terkandung nilai-nilai pendidikan, sosial, budaya, sejarah, bahkan imajinasi yang mampu menumbuhkembangkan karakter pada peserta didik.

One day one dongeng dapat dijadikan sarana efektif bagi pendidik dan orang tua dalam menanamkan karakter gemar membaca peserta didik, sebab masa pandemi merupakan peluang yang besar bagi orang tua untuk mengenalkan dongeng dan sebagai bagian dari perwujudan gerakan literasi. Beberapa penelitian terdahulu mengungkap tentang one day one dongeng, diantaranya Rahmawati (2016) yang menyatakan bahwa one day one dongeng sebagai upaya untuk membudayakan literasi dini. Penelitian ini menjabarkan bagaimana one day one dongeng sebagai terobosan baru dalam membangun budaya literasi pada anak usia dini. Minat baca akan terbangun melalui kebiasan membacakan dongeng kepada anak setiap hari. Penelitian ini menyimpulkan bahwa metode yang paling mudah dalam membudayakan literasi pada anak yaitu dengan one day one dongeng.

Selanjutnya, penelitian yang dilakukan oleh Mizani (2018) yang menyimpulkan bahwa pelaksanaan strategi one day one dongeng menimbulkan sikap antusias untuk membaca pada anak putus sekolah di desa Lemahbang. Dari beberapa penelitian terdahulu tentang one day one dongeng hanya mengungkap pada kajian tentang literasi secara umum belum pada menyentuh karakter gemar membaca dan juga bukan pada kondisi yang agak sulit yaitu pandemi Covid-19 ini. Perbedaan dengan penelitian ini yaitu pada pembahasan tentang one day one dongeng sebagai metode untuk menanamkan karakter gemar membaca pada masa pandemi dan dapat dijadikan model pembelajaran literasi bagi pendidik dan orang tua yang mendukung program literasi pemerintah. 


\section{Metode Penelitian}

Penelitian ini merupakan penelitian deskriptif kualitatif, yang bertujuan untuk mendeskripsikan secara komprehensif tentang konsep penanaman karakter gemar membaca melalui one day one dongeng bagi peserta didik sekolah dasar. Pendekatan yang digunakan pada penelitian ini menggunakan metode analisis isi/content analysis. Menurut Fraenkel \& Wallen (2007: 483), metode analisis isi/content analysis merupakan teknik yang dapat digunakan oleh peneliti untuk menganalisis perilaku manusia terhadap komunikasi mereka, semacam buku bacaan, essai, koran, majalah, novel, cerpen, artikel, iklan, poster, dan semua jenisnya yang bisa dianalisis. Dalam penelitian ini, peneliti menganalisis bagaimana one day one dongeng dapat dijadikan pilihan atau metode dalam menanamkan karakter gemar membaca selama masa pandemi Covid-19. Adapun sumber data penelitian ini yaitu berupa buku dan artikelartikel jurnal terkait metode one day one dongeng. Obyek penelitian ini yaitu strategi one day one dongeng dalam menanamkan karakter gemar membaca bagi peserta didik sekolah dasar pada masa pandemi Covid-19.

\section{Hasil dan Pembahasan}

\subsection{Hasil}

\subsubsection{One Day One Dongeng}

Dongeng merupakan salah satu karya sastra berbentuk prosa yang menggambarkan cerita fiktif sebagai hiburan, namun menitipkan beberapa pesan moral dan sebagian besar diperuntukan kepada anak-anak. Senada dengan Kamisa dalam Habsari (2017: 24) yang menjelaskan bahwa dongeng adalah cerita yang dituturkan atau dituliskan yang bersifat hiburan dan biasanya tidak benar-benar terjadi dalam kehidupan. Sebagian besar dongeng mengisahkan tentang manusia, hewan, tumbuhan, dan bahkan apapun yang ada di sekitar dapat dijadikan dongeng. Beberapa ahli mengungkapkan jenis-jenis dongeng, salah satunya adalah Aarne dan Thompson dalam Danandjaja (2007: 86) yang mengategorikan dongeng menjadi empat bagian, yaitu: (1) dongeng binatang (animals tales), (2) dongeng biasa (ordinary folktales), (3) lelucon dan anekdot (jokes and anecdotes), dan (4) dongeng berumus (formula tales).

Empat kategori dongeng yang diuraikan di atas adalah dua jenis dongeng yang sering digunakan untuk pembelajaran kepada anak-anak, yaitu dongeng binatang dan dongeng biasa. Beberapa judul dongeng familiar di kalangan anak Indonesia adalah "Si Kancil" dengan tokoh utama Kancil yang berkarakter binatang cerdik dan selalu mengalahkan tokoh antagonis, seperti binatang Buaya, Singa, Monyet, Serigala, dan lain-lain. Namun, di lain cerita Kancil menjadi karakter antagonis (angkuh) kalah dengan siput dan kura-kura yang kecepatannya lebih lambat darinya. Sementara dongeng biasa (ordinary folktales) ditokohkan oleh manusia dan sebagian besar mengisahkan suka duka kehidupan. Judul dongeng biasa yang sudah mengakar di otak dan hati anak-anak, baik dari Indonesia atau mancanegara adalah "Bawang Merah Bawang Putih", "Sangkuriang", "Malin Kundang", "Cinderella", dan lain-lain. Beberapa judul dongeng tersebut dapat dikatakan sebuah legenda, yakni menceritakan asal mula suatu tempat.

Beberapa jenis dongeng tersebut, terlebih judul dongeng yang tertera memiliki pesan moral yang dapat diberdayakan sebagai sumber pembentukan karakter anak. Namun, pendongeng (orang tua atau guru) dapat mem-filter dongeng sesuai dengan usia (Kusmiadi, Sriwahyuningsih, \& Nurfalah, 2008: 198), perkembangan psikologi, dan minat anak. Dongeng memiliki banyak manfaat bagi anak-anak. Hal ini dijelaskan oleh 
Noor dalam Wijaya \& Mulyati (2018: 50) bahwa terdapat enam manfaat dongeng bagi anak-anak, yaitu: (1) mengajarkan nilai moral yang baik, (2) mengembangkan daya imajinasi anak, (3) menambah wawasan, (4) meningkatkan kreativitas, (5) mendekatkan anak-anak dengan orang tua, dan (6) menghilangkan ketegangan atau stres.

Metode one day one dongeng merupakan salah satu metode yang dapat diterapkan semua pendongeng, baik orang tua maupun guru kepada anak-anak untuk menumbuhkan karakter gemar membaca. Penanaman karakter gemar membaca untuk anak-anak diawali dengan dongeng, namun sebelum terimplementasi metode one day one dongeng, adanya program yang harus dilaksanakan secara timeline agar terbentuknya metode/manajemen one day one dongeng. Dongeng merupakan salah satu daya tarik anak-anak untuk membaca. Dewasa ini sebagian besar anak-anak di Indonesia lebih gemar menonton dibanding membaca, karena kurang difasilitasi media oleh orang tua, selain itu sebagian besar orang tua kurang peduli dengan penanaman gemar membaca dan lebih menyerahkan kepada guru. Pada dasarnya metode one day one dongeng ini tidak membutuhkan keahlian khusus, hanya saja orang tua dituntut untuk lebih sabar dan teliti dalam menerapkan metode ini. Sebagaimana yang telah diungkapan bahwa salah satu manfaat penerapan metode tersebut adalah menanamkan pendidikan karakter.

Langkah-langkah timeline untuk membentuk manajemen one day one dongeng adalah sebagai berikut: (1) membuat kurikulum one day one dongeng, (2) memberikan pemahaman kepada anak pentingnya membaca, (3) membuat taman baca di rumah, dan (4) mengimplementasikan one day one dongeng sesuai kurikulum. Kurikulum one day one dongeng yang dapat diterapkan pada pendidikan informal di masa Covid adalah sebagai berikut:

Tabel 1. Kurikulum One Day One Dongeng yang dapat Diterapkan pada Pendidikan Informal di Masa Covid

\begin{tabular}{|c|c|c|c|}
\hline Materi & Teknik & Kegiatan & Tujuan \\
\hline $\begin{array}{l}\text { Menyimak } \\
\text { dongeng } \\
\text { (animals } \\
\text { tales) }\end{array}$ & Menyimak estetik & $\begin{array}{lr}\text { Anak menyimak } \\
\text { dongeng, namun sebelum } \\
\text { dongeng dibacakan, anak } \\
\text { memberi petunjuk- } \\
\text { petunjuk. Pada saat } \\
\text { menyimak isi dongeng, } \\
\text { orang tua menekankan } \\
\text { emosional } \\
\text { menghayati dan timbul } \\
\text { rasa senang terhadap } \\
\text { dongeng. } \\
\text { Setelah menyimak, anak } \\
\text { diminta memberikan } \\
\text { feedback. }\end{array}$ & $\begin{array}{l}\text { Membangkitkan rasa } \\
\text { ingin tahu dan minat } \\
\text { membaca anak. }\end{array}$ \\
\hline $\begin{array}{l}\text { Membaca } \\
\text { dongeng } \\
\text { (animals } \\
\text { tales) }\end{array}$ & $\begin{array}{l}\text { - Membaca } \\
\text { gambar } \\
\text { - Story telling } \\
\text { menggunakan } \\
\text { boneka } \\
\text { tangan/tokoh }\end{array}$ & $\begin{array}{l}\text { Memfasilitasi anak-anak } \\
\text { berbagai buku (dongeng) } \\
\text { fabel, meminta anak- } \\
\text { anak untuk memilih buku } \\
\text { yang diminati, } \\
\text { memberikan kesempatan }\end{array}$ & $\begin{array}{l}\text { Meningkatkan } \\
\text { kemampuan berbahasa, } \\
\text { menanamkan budaya } \\
\text { membaca, dan mengasah } \\
\text { imajinasi. }\end{array}$ \\
\hline
\end{tabular}




\begin{tabular}{|c|c|c|c|}
\hline Materi & Teknik & Kegiatan & Tujuan \\
\hline & $\begin{array}{l}\text { yang } \\
\text { digambarkan }\end{array}$ & $\begin{array}{l}\text { kepada anak } \begin{array}{r}\text { untuk } \\
\text { dan }\end{array} \\
\text { bertanya } \\
\text { berkomentar tentang } \\
\text { buku yang dipilih, } \\
\text { memberikan kesempatan } \\
\text { untuk membaca kisah } \\
\text { dari gambar, dan } \\
\text { disambut dengan story } \\
\text { telling menggunakan } \\
\text { media. }\end{array}$ & \\
\hline \multicolumn{4}{|c|}{ EVALUASI-ISTIRAHAT } \\
\hline $\begin{array}{l}\text { Menyimak } \\
\text { dongeng } \\
\text { (animals } \\
\text { tales dan } \\
\text { ordinary } \\
\text { folktales) }\end{array}$ & Menyimak kreatif & $\begin{array}{lr}\text { Anak menyimak cerita } \\
\text { dari pendongeng } & \text { (orang } \\
\text { tua, saudara, atau } & \text { dengan } \\
\text { pengasuh) } & \text { senang. } \\
\text { perasaan } & \text { dapat } \\
\text { Pendongeng } & \text { memvisualisasikannya } \\
\text { dengan gestur tubuh dan } & \\
\text { mimik sesuai dongeng } \\
\text { yang dibawakannya. } \\
\text { Pendongeng dapat } \\
\text { menggunakan media } \\
\text { sekitar yang dianggap } \\
\text { menarik perhatian anak. }\end{array}$ & $\begin{array}{l}\text { Menyimak dongeng } \\
\text { (animals tales dan } \\
\text { ordinary folktales). }\end{array}$ \\
\hline $\begin{array}{l}\text { Membaca } \\
\text { dongeng } \\
\text { (animals } \\
\text { tales dan } \\
\text { ordinary } \\
\text { folktales) }\end{array}$ & Membaca nyaring & 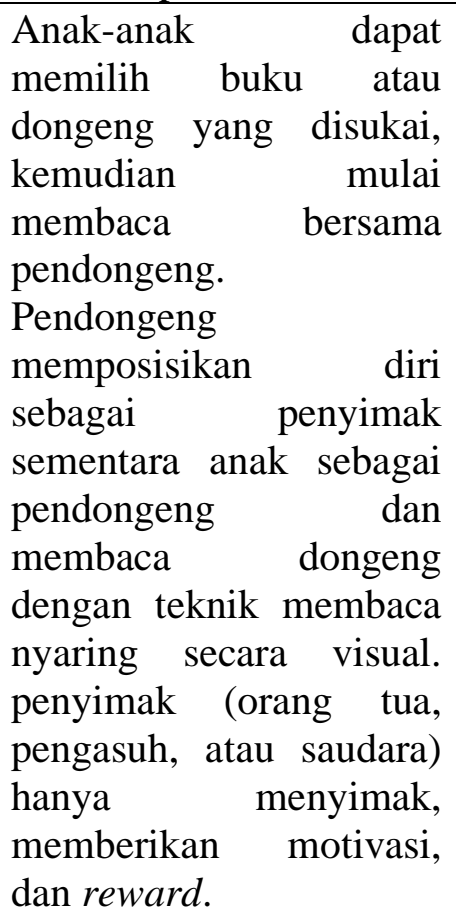 & $\begin{array}{l}\text { Membaca dongeng } \\
\text { (animals tales dan } \\
\text { ordinary folktales). }\end{array}$ \\
\hline
\end{tabular}


Kurikulum dibentuk berdasarkan hasil pengamatan kepada anak-anak yang belum terbiasa membaca dan perlu diimplementasikan setiap hari, agar dapat mengurangi kebiasaan anak bermain gadget, mengurangi kemalasan, meningkatkan kecerdasan, dan menanamkan pribadi yang gemar membaca di masa pandemi Covid-19, terlebih dapat mempererat hubungan keluarga (Fitroh \& Sari, 2015: 97).

\subsubsection{Karakter Gemar Membaca}

Salah satu ritual penting untuk anak agar tertanam jiwa gemar membaca adalah bantuan guru, orang tua, atau pendongeng untuk memberikan pemahaman tentang AMBak. AMBak adalah akronim dari Apa Manfaat Bagiku?, jika anak telah memahami membaca membawa efek baik bagi dirinya, maka secara tidak langsung akan tertanam gemar membaca (Sari, 2018: 210). Anak yang gemar membaca akan berlama-lama untuk membaca dan sudah ter-mindset menyediakan waktunya untuk membaca setiap hari, sehingga tertanam sikap positif dalam lingkungan informal, formal, dan non formal.

\subsection{Pembahasan}

Bedasarkan timeline dan kurikulum yang sudah tersusun, perlu ditanamkan secara berkelanjutan terlebih pada masa Covid-19 ketika anak-anak lebih bersahabat dengan gadget dibandingkan dengan buku walaupun buku bergambar, sehingga terjadi degradasi moral. Namun, dari sisi positif adalah dapat mendidik anak di rumah tanpa terikat waktu, belajar dari rumah bersifat alamiah, dan orang tua harus berpartisipasi secara aktif untuk menjadi guru yang menyenangkan bagi anak. Sebagai orang tua yang memiliki tanggung jawab mendidik anak, perlu diterapkan manajemen one day one dongeng. Pemahaman AMBAk? yang diberikan kepada anak tidak terkesan mendikte namun lebih friendly agar anak merasakan kenyamanan.

Beberapa hal yang perlu dilakukan dalam memberikan pemahaman AMBAk? yaitu: (1) menjadikan orang tua sebagai panutan dalam membaca, anak tidak akan gemar membaca jika orang tua tidak gemar membaca. Orang tua dapat memberikan halhal positif ketika menghabiskan waktu bersama anak, sehingga orang tua dapat menentukan karakter anak, (2) membuat setiap kegiatan menjadi menyenangkan, seperti membantu membersihkan mainan dan setelahnya mendapat reward berupa dongeng bergambar dari kegiatan yang telah dilakukan, (3) memberikan kepercayaan untuk bertanggungjawab, sekarang ini banyak orang tua yang kurang mengenal perkembangan anak. Ketika masa golden age anak penuh rasa ingin tahu, oleh karena itu berikan kepercayaan untuk melakukan sesuatu, dan (4) memberikan motivasi, minat, dan bakatnya. Beberapa kegiatan tersebut terlihat tidak siginifkan terhadap buku namun ini dapat meningkatkan konsentrasi anak dalam melakukan sesuatu dan mengembangkan minat bacanya.

Sebagian besar sekolah tingkat dasar terdapat pojok baca guna menumbuhkan budaya literasi di sekolah. Namun, pada masa pandemi Covid-19 anak tidak dapat membaca seperti biasa yang diprogramkan sekolah, sehingga orang tua yang menggerakkan pendidikan informal harus membudayakan literasi di rumah dengan cara membuat taman baca di rumah. Taman baca di rumah bukan sekedar koleksi buku, namun perlu diterapkan jadwal membaca setiap hari. Kurikulum one day one dongeng dapat dijadikan referensi untuk jadwal membaca anak. Kurikulum one day one dongeng dibentuk berdasarkan penerapan kepada beberapa anak, agar gemar membaca dan kurikulum ini sangat membawa dampak positif jika diterapkan pada masa pandemi Covid-19. Selain itu, formula kurikulum tersebut berdasarkan hubungan keterampilan. 
Berawal dari menyimak, ketika anak telah difasilitasi taman baca pribadi di rumah, maka dapat diberikan beberapa dongeng menarik. Anak diarahkan untuk memillih dongeng yang paling disukai, sebagian besar anak-anak memilih dari unsur cover. Setelah memilih, anak diminta untuk menyimak dongeng yang dibacakan orang tua dan sudah pasti orang tua dapat membacakan dongeng sesuai karakter dalam dongeng agar anak terhindar dari kehilangan fokus. Orang tua dapat menggunakan media yang tersedia di rumah, seperti kaos kaki, selimut, boneka, dan jari tangan.

Orang tua dapat menggunakan teknik estetik, dapat dikatakan pula menyimak apresiatif, sudah pasti karena yang bacakan orang tua adalah dongeng atau karya sastra. Keberhasilan orang tua dalam membawakan dongeng jika anak terhipnotis oleh cerita yang dibawakannya, anak terhanyut oleh karakter yang ada dalam dongeng tersebut. Menyimak estetik dapat diputuskan di pertengahan dongeng guna untuk mencari tingkat fokus anak, jika tingkat kefokusannya mengalami degradasi. Agar tingkat kefokusan anak kembali normal, orang tua dapat menggunakan cara teka-teki. Contohnya yaitu kelinci berlari secepat mungkin, berlari, dan berlari hingga tiba di garis finish. Kelinci menoleh ke belakang, ngeekkk... "Hmm kura-kura belum terlihat rupanya, bagaimana jika aku tidur dulu? sepertinya pohon itu cukup rindang.. Aku tidur dulu ahh" Ketika itu... Apa yang terjadi? Kamu tahu? Coba kita tebak apa yang terjadi jika kelinci tertidur?.

Secara refleks, anak bergegas menjawab pertanyaan meskipun salah namun tingkat kefokusannya kembali normal. Orang tua dapat melanjutkan cerita setelah tekateki terjawab hingga selesai. Anak-anak adalah penanti reward. Pemberian reward dimaksudkan untuk membentuk anak lebih giat lagi. Usahanya untuk bekerja dan berbuat lebih baik lagi (Anggraini, Siswanto, \& Sukamto, 2019: 223). Reward dapat diberikan jika anak dapat memberikan feedback dari cerita yang sudah dibacakan. Sehingga, dapat disimpulkan bahwa anak tertarik atau tidak tentang dongeng yang dibacakan. Jika tertarik, anak akan memilih dongeng yang lain dan meminta orang tua membacakan kembali.

Orang tua dapat menerima feedback dari hasil simakan di hari sebelumnya dengan cara anak diminta membacakan dongeng untuk orang tua. Di sinilah tantangan terbesar orang tua dan harus menurunkan emosional, agar anak dapat membaca sesuai harapan orang tua. Orang tua dapat berperan seperti seorang anak kecil yang diminta untuk dibacakan dongeng oleh gurunya sementara anak sebagai guru. Bermain peran seperti ini lebih efektif dibandingkan orang tua menginstruksikan secara tegas. Anakanak dapat membaca dongeng sesuai kemampuan, dapat membaca dari gambar, dan dapat bercerita secara lancar sesuai dengan usianya. Tingkat kematangan cerita bergambar adalah usia dua hingga tujuh tahun karena dianggap golden age dan sedang masa tahapan produksi ujaran (Arsanti, 2014: 38).

Story telling sebagian besar dilakukan oleh anak usia delapan hingga sepuluh tahun karena dianggap sudah dapat membaca secara lancar. Orang tua harus bertanya kepada anak tentang tokoh dan penokohan yang ada dalam dongeng tersebut, seperti siapa tokohnya dan bagaimana karakternya, tokoh yang disukai, mengapa menyukainya, apakah tokoh tersebut baik atau buruk, dan bolehkah meniru karakter tokoh yang baik atau sebaliknya. Pertanyaan tersebut untuk mendapatkan hasil bacaan, memahami atau tidaknya dengan bacaan tersebut. Semua penggambaran watak, sifat, dan karakter tokoh harus logis dan masuk akal agar lebih mudah diterima oleh anak (Wachidah, Suwignyo, \& Widiati, 2017: 894). 
Meskipun secara bahasa kegiatan one day one dongeng adalah satu hari satu dongeng, bukan berarti anak disuguhkan dongeng setiap hari tanpa istirahat. Istirahat dimaksud adalah memberikan reward kepada anak untuk menonton televisi atau menonton youtube dengan arahan dan waktu tertentu. Pada saat bersamaan, orang tua dapat mengevaluasi hasil simakan dan bacaan anak. Hasil simakan tersebut dapat diupgrade sesuai karakter anak di hari berikutnya dengan metode yang sama namun materi berbeda. Hasil penanaman karakter gemar membaca dongeng tidak instan, orang tua harus membelakangi egonya untuk menekan anak agar dapat gemar membaca. Hal ini dikarenakan fase golden age adalah masanya anak-anak gemar bermain dan bermanja. Pada saat inilah anak mengalami akselarasi otak. Sementara anak pada usia tujuh hingga empat belas tahun, orang tua dapat mengenalkan disiplin kepada anak, sehingga kurikulum one day one dongeng dapat di-upgrade.

\section{Simpulan}

Penanaman karakter gemar membaca dapat ditumbuh kembangkan meski masa pandemi Covid 19 ini, salah satunya melalui penerapan one day one dongeng. Pemilihan konsep one day one dongeng dimaksudkan bahwa dongeng mengandung nilai-nilai pendidikan, sosial, budaya dan mampu menumbuhkan imajinasi peserta didik. Kegiatan yang dapat dilakukan untuk menanamkan karakter gemar membaca sebaiknya kegiatan yang bersifat santai, ringan, menarik, bahkan lucu. Dari empat jenis dongeng yang familiar digunakan pada anak adalah dongeng binatang (animals tales) dan dongeng biasa (ordinary folktales). Dalam penyampaian dongeng harus memahami tekniknya agar anak-anak dapat memahami isi dari dongeng tersebut. Teknik menyimak dan membaca pada pengembangan one day one dongeng yang tepat digunakan adalah menyimak estetik dan menyimak kreatif, sementara membaca adalah membaca gambar, story telling, dan membaca nyaring. Teknik tersebut dapat digunakan secara terus menerus, sehingga tertanam karakter gemar membaca bagi generasi alpha.

\section{Daftar Pustaka}

Anggraini, S., Siswanto, J., \& Sukamto. (2019). Analisis Dampak Pemberian Reward and Punishment bagi Siswa SD Negeri Kaliwiru Semarang. Mimbar PGSD Undiksha, 7(3), 221-229. https://doi.org/10.23887/jjpgsd.v7i3.19393

Ansori, A., \& Sari, A. F. (2020). Inovasi Pendidikan di Masa Pandemi Covid-19. Jurnal Literasi Pendidikan Nusantara, 1(2), 133-148. http://jurnal.uinbanten.ac.id/ind ex.php/jlpn/article/view/3735

Arsanti, M. (2014). Pemerolehan Bahasa pada Anak (Kajian Psikolinguistik). Jurnal PBSI, 3(2), 24-47. http://research.unissula.ac.id/file/publikasi/211315023/3959t PEMEROLEHAN_BAHASA_PADA_ANAK.pdf

Central Connecticut State University. (2017). World's Most Literate Nations. Www.Cc su.Edu. https://www.ccsu.edu/wmln/rank.html

Damayanthi, A. (2020). Efektivitas Pembelajaran Daring di Masa Pandemi Covid-19 pada Perguruan Tinggi Keagamaan Katolik. Edutech, 19(3), 189-210. https:// doi.org/10.17509/e.v1i3.26978

Danandjaja, J. (2007). Folklor Indonesia Ilmu Gosip, Dongeng, dan Lain-Lain. PT. Temprint.

Fitroh, S. F., \& Sari, E. D. N. (2015). Dongeng sebagai Media Penanaman Karakter pada Anak Usia Dini. Jurnal PG-PAUD Trunojoyo: Jurnal Pendidikan dan 
Pembelajaran Anak Usia Dini, 2(2), 95-105. https://doi.org/10.21107/pgpaud trunojoyo.v2i2.2606

Fraenkel, J. C., \& Wallen, N. E. (2007). How to Design and Evaluate Research in Education. McGraw-Hill, inc.

Habsari, Z. (2017). Dongeng sebagai Pembentuk Karakter Anak. BIBLIOTIKA: Jurnal Kajian Perpustakaan dan Informasi, 1(1), 21-29. https://doi.org/10.17977/ um008v1i12017p021

Kusmiadi, A., Sriwahyuningsih, \& Nurfalah, Y. (2008). Strategi Pembelajaran PAUD melalui Metode Dongeng bagi Pendidik PAUD. Jurnal Ilmiah VISI PTK-PNF, 3(2), 198-203. https://doi.org/10.21009/jiv.0302.11

Lutfi, Sumardi, A., Farihen, \& Ilmia, G. (2020). Pendampingan Kegiatan Membaca untuk Meningkatkan Kemampuan Literasi Siswa Sekolah Dasar pada Masa Pandemi Covid-19. Seminar Nasional Pengabdian Masyarakat LPPM UMJ, 15. https://jurnal.umj.ac.id/index.php/semnaskat/article/view/8069

Marwa, Munirah, Angriani, A. D., Suharti, Sriyanti, A., \& Rosdiana. (2020). Peran Guru dalam Meningkatkan Minat Belajar Peserta Didik Kelas IV pada Masa Pandemi Covid-19. AULADUNA: Jurnal Pendidikan Dasar Islam, 7(2), 215227. https://doi.org/10.24252/10.24252/auladuna.v7i2a10.2020

Mizani, M. A. I. (2018). Program One Day One Book Startegi Literasi Pendidikan Anak Putus Sekolah di Desa Lemahbang. Proceeding of The 8th University Research Colloquium 2018: Bidang Pendidikan, Humaniora, dan Agama, 290-296. http://repository.urecol.org/index.php/proceeding/article/view/445

Nadeak, B., Naibaho, L., Sunarto, Tyas, E. H., \& Sormin, E. (2021). Learning Management in Suburban Schools During the Midst of Covid-19. Psychology and Education Journal, 58(2), 1131-1139. https://doi.org/10.17762/pae.v58i2. 2252

Novari, A. F., Ardini, F. M., Rostiana, H., Meliyawati, Widiatmoko, M., Rohimajaya, N. A., Gumelar, R. E., \& Sauri, S. (2020). Optimalisasi Minat Baca Anak Desa Medalsari di Masa Pandemi melalui Storytelling. Jurnal Pengabdian pada Masyarakat, 5(3), 646-655. https://doi.org/10.30653/002.202053.599

Rahman, Sakti, A. W., Widya, R. N., \& Yugafiati, R. (2019). Elementary Education Literacy in the Era of Industrial Revolution 4.0. UPI 2nd International Conference on Language, Literature, Culture, and Education (ICOLLITE 2018) Elementary, 257, 190-193. https://doi.org/10.2991/icollite-18.2019.41

Rahman, Tristiantari, N. K. D., Zakaria, \& Yugafiati, R. (2020). Learning from Home (Revitalization of Masatua to Improve Students' Literacy in Elementary School). 4th International Conference on Language, Literature, Culture, and Education (ICOLLITE 2020), 504, 605-609. https://doi.org/10.2991/assehr.k.201215.094

Rahmawati, I. Y. (2016). One Day One Dongeng sebagai Upaya untuk Membudayakan Literasi pada Anak Usia Dini. Budaya Literasi untuk Menumbuhkan Generasi Cendekia dan Literat 2016, 45-54. http://pbsi.fbs.uny.ac.id/sites/pendidikanbahasa-sastra-indonesia.fbs.uny.ac.id/files/PROSIDING SEMINAR NASIONA L JPBSI FBS UNY 2016_ BUDAYA LITERASI UNTUK MENUMBUHKAN GENERASI CENDEKIA DAN LITERAT.pdf

Sari, P. P. (2018). Penanaman Nilai Karakter Gemar Membaca. Jurnal Ilmiah Mahasiswa Raushan Fikr, 7(2), 205-217. https://doi.org/10.24090/jimrf.v7i2.25 21

Tahmidaten, L., \& Krismanto, W. (2020). Permasalahan Budaya Membaca di Indonesia 
(Studi Pustaka tentang Problematika \& Solusinya). Scholaria: Jurnal Pendidikan dan Kebudayaan, 10(1), 22-33. https://doi.org/10.24246/j.js.2020. v10.i1.p22-33

Wachidah, L. R., Suwignyo, H., \& Widiati, N. (2017). Potensi Karakter Tokoh dalam Cerita Rakyat sebagai Bahan Bacaan Literasi Moral. Jurnal Pendidikan: Teori, Penelitian, dan Pengembangan, 2(7), 894-901. https://doi.org/10.17977/JPTPP. V2I7.9620

Wijaya, R. A., \& Mulyati, Y. (2018). Sastra Dongeng dalam Pembelajaran Membaca dan Menulis Permulaan. Deiksis: Jurnal Pendidikan Bahasa dan Sastra Indonesia, 5(1), 47-56. https://doi.org/10.33603/deiksis.v5i1.860 